\title{
Interference Effects During Burning in Air for Stationary n-Heptane, Ethyl Alcohol, and Methyl Alcohol Droplets'
}

\author{
J. F. REX, ${ }^{2}$ A. E. FUHS, ${ }^{3}$ and S. S. PENNER ${ }^{4}$ \\ Daniel and Florence Guggenheim Jet Propulsion Center, California Institute of Technology, Pasadena, Calif.
}

\begin{abstract}
Experiments have been conducted for the determination of the evaporation constant and flame shapes of two and of five closely spaced droplets burning in air. Droplets of approximately the same and of different diameters were used at various distances between the droplet centers. The apparent flame shape, which was observed only for $n-$ heptane droplets, changes very little during burning. The square of the droplet diameter decreases linearly with time for fixed spacing between droplet centers, at least within the experimental limits of accuracy. In general, the average evaporation constant for two droplets, $\bar{K}^{\prime}$, must be assumed either to vary continuously during burning or else to be a function of average initial drop diameter, $\bar{D}^{0}$. The change of $\bar{K}^{\prime}$ with time corresponds to the second derivative in plots of the square of the diameter vs. time. These second derivatives are not defined in our work because of unavoidable scatter of the experimental data. Attempts at understanding the observed results by considering published theories for single droplets, as well as groupings obtained from dimensional analysis, have been unsuccessful. It appears that the diffusion model for the heterogeneous burning of single fuel droplets will require serious revision and extension before the burning of droplets arrays and sprays can be understood quantitatively. Furthermore, the effective value of $K^{\prime}$ for a spray probably depends not only on the fuel-oxidizer system but also on the injection pattern. For this reason additional studies had best be carried out under conditions corresponding to those existing in service models.
\end{abstract}

\section{Nomenclature}

$a$

$b$

$C^{0}$

C

$D^{0}$

$D$

$K^{\prime}$

\footnotetext{
$=$ vertical distance from center of droplet to lower flame surface

$=$ horizontal distance from center of droplet to outside flame surface

$=$ initial minimum distance between adjacent droplet surfaces

$=$ minimum distance between adjacent droplet surfaces at time $t$

$=$ initial droplet diameter

$=$ droplet diameter at time $t$

$=$ evaporation constant

= evaporation frequency
}

Presented at the ARS Fall Meeting, Los Angeles, Calif., Sept. 18-21, 1955.

${ }^{1}$ Supported by the Office of Ordnance Research, U. S. Army, under Contract DA O4-495-Ord-446. The authors are indebted to Mr. D. Weber for help with the experimental work and to $\mathrm{Mr}$. D. East for assistance with computations and film reading.

2 Lt., U. S. Navy. This article is based, in part, on a thesis submitted by J. F. Rex to the Graduate School of the California Institute of Technology in partial fulfilment of requirements for the degree of Aeronautical Engineer, June 1955.

${ }^{3}$ Graduate student in mechanical engineering, jet propulsion option. Stud. Mem. ARS.

4 Associate Professor of Jet Propulsion. Mem. ARS.

- Numbers in parentheses indicate References at end of paper.

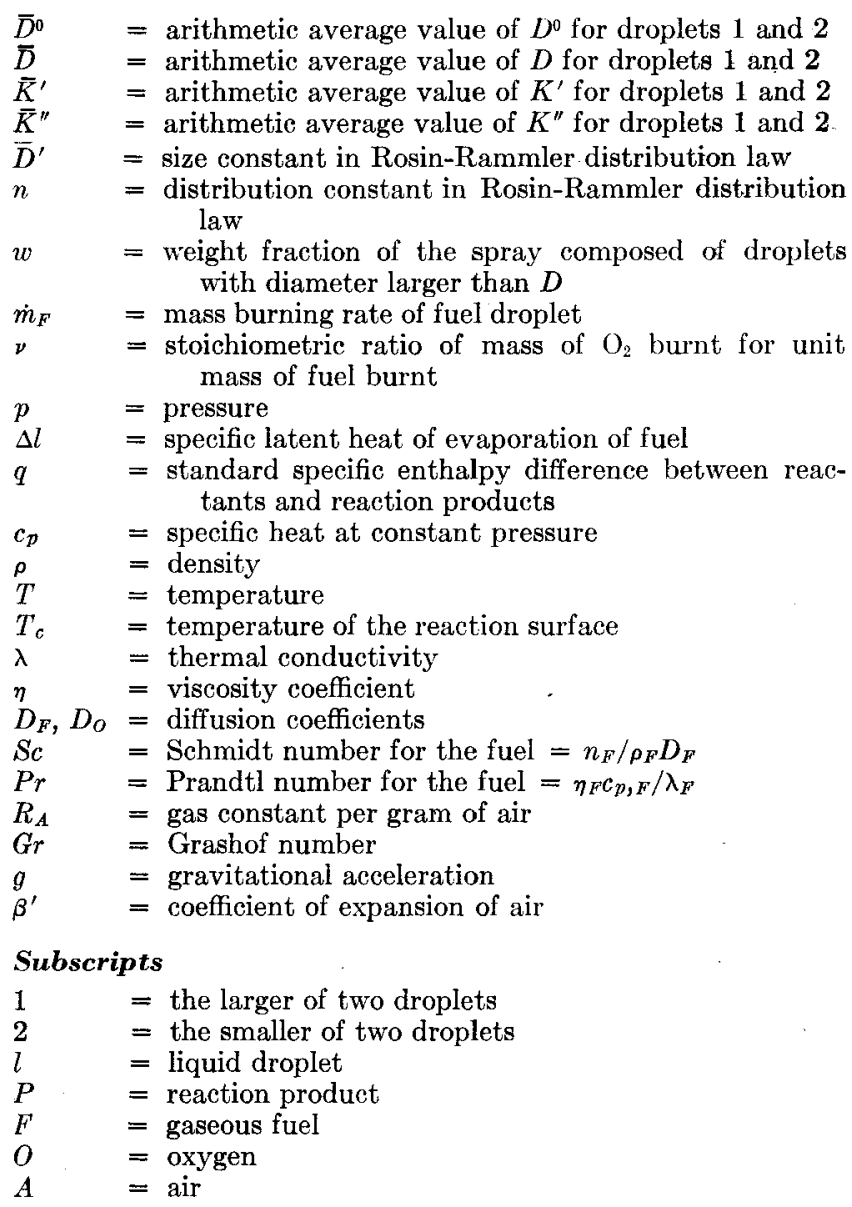

\section{Introduction}

A CONSIDERABLE number of theoretical and experiA mental papers has been published on the burning of single droplets of fuel (1-5). ${ }^{5}$ Experimental studies have been performed on single droplets suspended from fine quartz fibers and burning in an oxidizing atomosphere (5). An approximate theoretical prediction of mass burning rate for single droplets can be obtained on the assumption that mass transport by diffusion to the flame surface and heat conduction to the burning droplet control the burning rate (4).

Recently an attempt has been made by Graves and Gerstein to utilize experimental data for single droplets in the description of burning rates in sprays (6). These authors started with the results of an important theoretical study carried out some years ago by Probert (7). Probert made the following assumptions:

(a) The spray particle size follows the Rasin-Rammler distribution law

$$
w=e^{\left(-D / \overline{D^{\prime}}\right)^{n}}
$$


where $w$ equals the volume fraction or weight fraction of the spray composed of drops with diameters greater than $D, \bar{D}^{\prime}$ is called the size constant, and $n$ is usually referred to as the distribution constant.

(b) The rate of burning of the droplets is taken to be proportional to the first power of the droplet diameter. In this case it is easily shown that

$$
D^{2}=\left(D^{0}\right)^{2}-K^{\prime} t
$$

where $D$ is the droplet diameter at any time, $D^{0}$ is the initial diameter, and $K^{\prime}$, which has the dimensions of area per unit time, is known as the evaporation constant.

Probert has shown how to compute the percentage of unburned fuel as a function of $\sqrt{K^{\prime}} t_{r} / \bar{D}^{\prime}$ for values of $n$ between 2 and 4 , where $t_{r}$ is the residence time of the burning droplets. Recently correlations similar to those of Probert have been worked out for droplet distribution laws other than the Rosin-Rammler distribution law (8).

Equation [2], which determines droplet diameter as a function of time, is known to correlate all of the observed results for the steady burning of single fuel droplets in an oxidizing atmosphere (4). Therefore, it is of obvious interest to determine whether or not the value of the evaporation constant, $K^{\prime}$, for single droplet theory or experiment has any relation to the value of $K^{\prime}$ appropriate for spray combustion. Graves and Gerstein attempted to answer this question by measuring the combustion efficiency as a function of oxygen concentration for a single tubular combustor using isooctane as fuel and countercurrent injection. They compared observed combustion efficiencies with calculated combustion efficiencies using Probert's theoretical analysis in conjunction with values of $K^{\prime}$ measured for the burning of single droplets. This comparison showed that all of the observed results could not be explained unless spray combustion involves effects, at least for oxygen concentrations below 24 per cent, which can be ignored in the burning of single droplets. In connection with the use of single droplet data for studies on spray combustion, it is therefore of obvious importance to carry out laboratory studies on interference between droplets during burning.

Although, as a general rule, statistical arrays are more easily interpreted than small numbers of droplets, such as 2 , 5, etc., experimental studies on small numbers of droplets may provide a clue for the important physico-chemical processes operative in droplet interference during burning. For this reason experiments have been carried out on the variation of $K^{\prime}$ with droplet size and droplet spacing for two and five closely spaced droplets.

We present in Section II a summary of experimental results obtained for n-heptane, ethyl alcohol, and methyl alcohol droplets. Attempts at finding simple correlations for the experimentally determined evaporation constants are outlined in Section III. Section IV contains some qualitative considerations relating to flame shapes for the burning of single stationary fuel droplets in air. Attempts at clarifying the observed data on the basis of results obtained from dimensional analysis form the subject of Section V.

\section{Experimental Studies on the Burning in Air of 'Two Stationary Fuel Droplets}

\section{A Apparatus}

In order to record the flame shape and the decrease in droplet diameter with time, the droplets were suspended on thin quartz fibers which were secured by means of Sauereisen cement to a metal rod. The rod was bent at an angle of 90 degrees and was supported on a stand by means of a clamp. Rods of various diameters were used for different minimum spacings between the adjacent surfaces of the droplets, $C^{0}$ (see Fig. 1). The fibers were either enclosed in a circular plastic tube of several inches diameter or else were burnt in

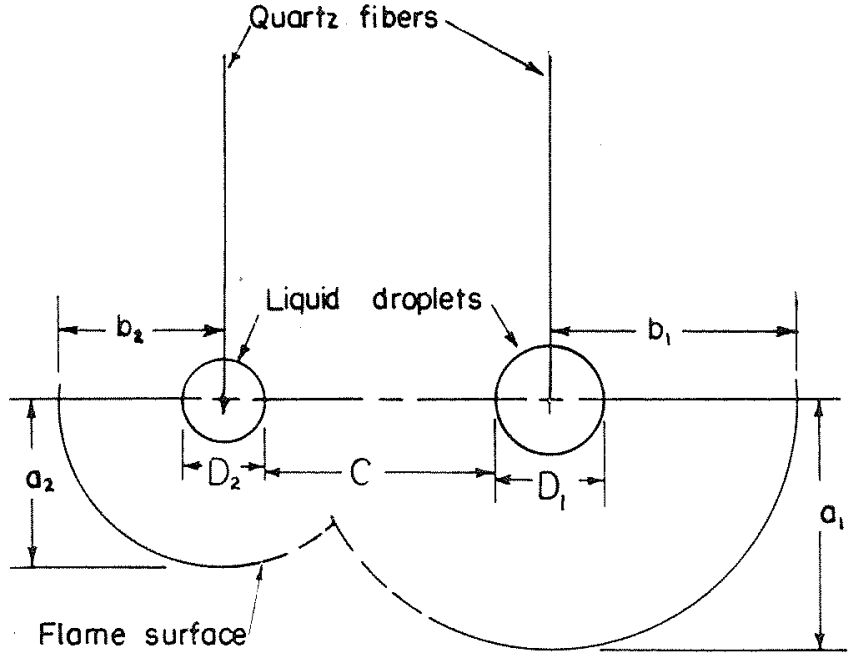

Fig. 1 Schematic arrangement of flame interference experiment with two droplets burning in close proximity

the open air; no significant differences between the burning rates were found in the two cases. Single droplets of fuel were suspended from the fibers by forcing fuel through a hypodermic needle onto the fiber. The droplets were reasonably spherical as shown, for example, in the photograph of Fig. 2. The drops were ignited by using either an automobile ignition system, connected to electrodes which straddled the two quartz fibers through holes in the tube (see Fig. 3), or else simply by using a match.

An electrically driven Arriflex 35-mm movie camera was used for photographing the burning droplets. A 100-watt bulb was placed behind the burning drops. Both a silhouette of the drops and the flame front were visible. A 10-inch adapter tube and telephoto lens were employed in order to obtain as large an image as possible on each frame of film. Kodak Plus X and Kodak Supper XX films were used with apertures of $\mathrm{f} 3.2$ to $\mathrm{f} 9$.

A stroboscope served as timing standard. A 10-inch circular aluminum plate, with three holes placed 120 degrees apart, was secured to a $75 \mathrm{rpm}$ constant-speed motor giving 3.75 flashes per second. The stroboscope was placed directly behind the burning drops. The camera speed was adjusted to about 25 frames per second.

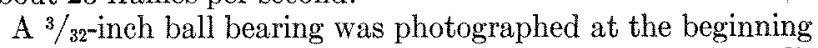
of each 100-ft roll of film used. The image served for calibration and was obtained under the same focusing conditions as were used for the burning droplets.

The film was measured by using a microfilm recorder and a steel scale graduated in millimeters. Two measurements were made on each drop, namely, the two perpendicular diameters inclined 45 degrees to the major and minor axes in the plane of observation. The mean value of these two readings was recorded as the "effective diameter" of the droplet. It is easily shown that, if the major and minor axes do not differ greatly, as was the case in our experiments, then the volume of a sphere with the measured effective diameter is not greatly different from that of the prolate spheroid, which actually corresponds to the shape of our droplets. In most cases measurements were taken from ignition to burn-out and recorded approximately every fifth or sixth frame. The flame shape parameters $a_{1}, a_{2}, b_{1}$, and $b_{2}$ (see Fig. 1) were also measured for $n$-heptane droplets.

\section{B Experimental Results Relating to Flame Shape and Burning Rate}

Experimental studies have been carried out for two stationary n-heptane, ethyl alcohol, and methyl alcohol droplets burning in air. The squars of the droplet diameter, $D^{2}$, was 


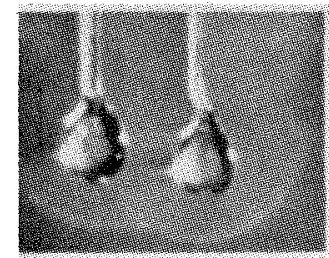

IGNITION

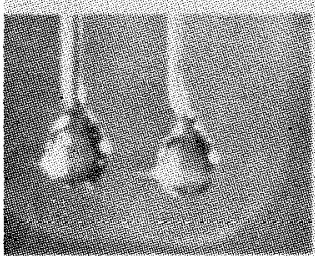

$T=0.53 \mathrm{SEC}$

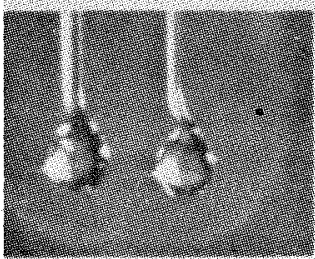

$T=0.75$ SEC.

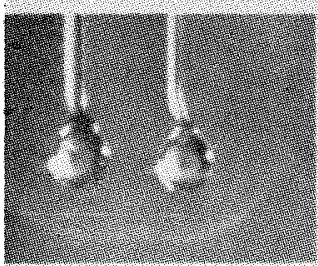

T=0.92 SEC.

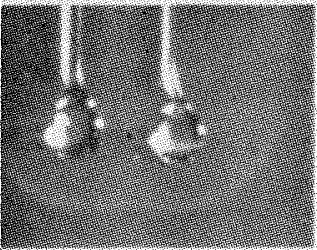

$T=128$ SEC

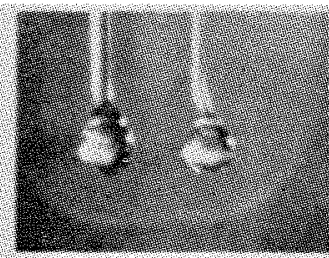

$T=1.44$ SEC

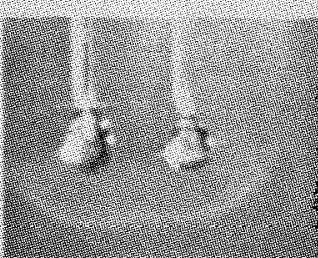

$T=1.70$ SEC.
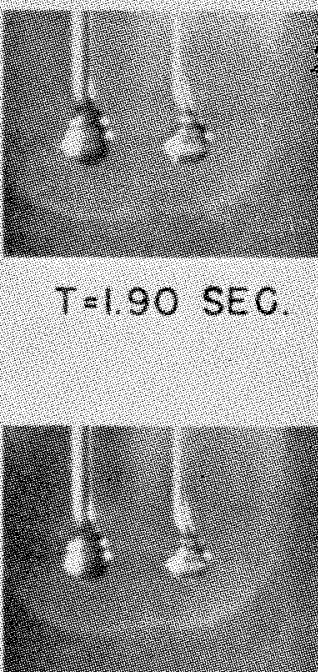

$T=2.15$ SEO

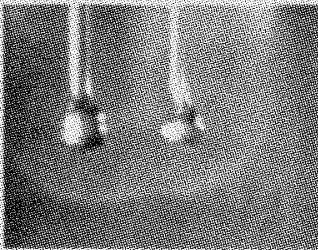

$T=2.40$ SEC.
$T=1.90$ SEC.

Fig. 2 Photograph of two n-heptane droplets burning in air $\left(D_{1}{ }^{0}=0.181 \mathrm{~cm} ; D_{2}{ }^{0}=0.174 \mathrm{~cm} ; C^{0}=0.114 \mathrm{~cm}\right)$

generally found to be a linear function of the time, $t$, for each of the burning droplets. The flame shape parameters (for n-heptane droplets) varied remarkably little with time as the droplets burned. Representative experimental results are shown in Figs. 4 to 10. The data plotted in Fig. 6 correspond to a case in which a relatively long time elapsed before steady burning occurred.

The experimental data obtained for $K^{\prime}$ are summarized in Tables 1 to 3 for n-heptane, ethyl alcohol, and methyl alcohol, respectively. The listed values of $K$ ' were obtained by drawing "best" straight lines through the experimentally deter-

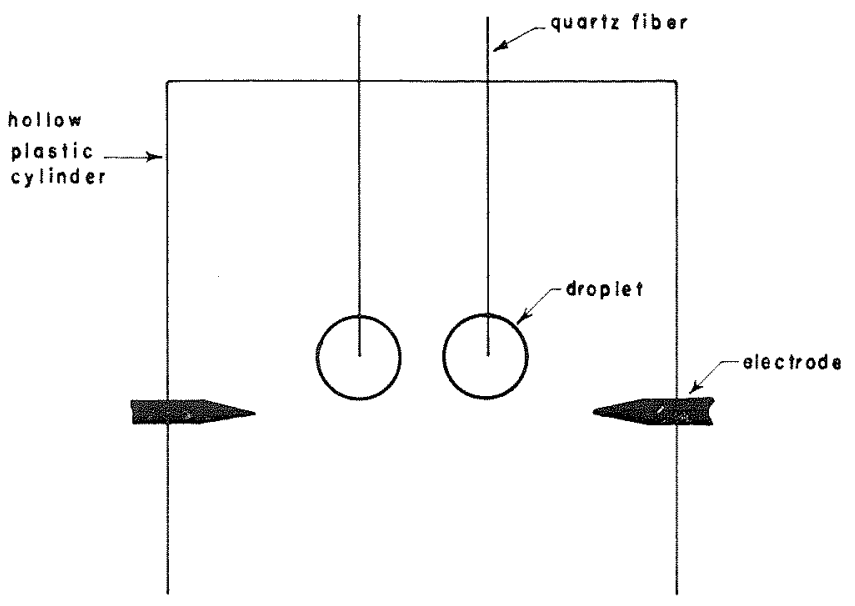

Fig. 3 Schematic diagram of apparatus used for droplet ignition

Table 1 Experimental results for two n-heptane droplets burning in still air

$\begin{array}{lllll}D_{1}{ }^{0} \mathrm{~cm} & D_{2}{ }^{0}, \mathrm{~cm} & C^{0}, \mathrm{~cm} & \begin{array}{c}K_{1}{ }^{\prime}, \\ \mathrm{cm}^{2} / \mathrm{sec}\end{array} & \begin{array}{c}K_{2}{ }^{\prime}, \\ \mathrm{cm}^{2} / \mathrm{sec}\end{array} \\ 0.194 & 0.166 & 0.020 & 0.0094 & 0.0082 \\ 0.166 & 0.174 & 0.114 & 0.0096 & 0.0094 \\ 0.192 & 0.154 & 0.183 & 0.0135 & 0.0130 \\ 0.165 & 0.176 & 0.230 & 0.0105 & 0.0096 \\ 0.182 & 0.173 & 0.264 & 0.0136 & 0.0122 \\ 0.182 & 0.182 & 0.892 & 0.0153 & 0.0141 \\ 0.173 & 0.173 & 1.125 & 0.0140 & 0.0140 \\ 0.182 & 0.156 & 1.47 & 0.0124 & 0.0133 \\ 0.130 & 0.127 & 0.222 & 0.0080 & 0.0115 \\ 0.138 & 0.134 & 0.208 & 0.0068 & 0.0063 \\ 0.135 & 0.117 & 0.313 & 0.0085 & 0.0085 \\ 0.124 & 0.124 & 0.235 & 0.0070 & 0.0070 \\ 0.133 & 0.122 & 0.540 & 0.0091 & 0.0090 \\ 0.136 & 0.120 & 0.496 & 0.0091 & 0.0068 \\ 0.121 & 0.118 & 0.384 & 0.0074 & 0.0074 \\ 0.143 & 0.142 & 0.533 & 0.0118 & 0.0110 \\ 0.141 & 0.135 & 0.538 & 0.0097 & 0.0093 \\ 0.155 & 0.142 & 0.496 & 0.0122 & 0.0114 \\ 0.156 & 0.147 & 0.813 & 0.0123 & 0.0113 \\ 0.156 & 0.141 & 0.883 & 0.0110 & 0.0112 \\ 0.156 & 0.156 & 1.10 & 0.0107 & 0.0108 \\ 0.208 & 0.155 & 0.120 & 0.0107 & 0.0104 \\ 0.209 & 0.170 & 0.352 & 0.0123 & 0.0109 \\ 0.198 & 0.140 & 0.375 & 0.0090 & 0.0089 \\ 0.167 & 0.115 & 0.520 & 0.0150 & 0.0090 \\ 0.160 & 0.131 & 0.532 & 0.0140 & 0.0150 \\ 0.192 & 0.148 & 0.026 & - & 0.0068 \\ 0.208 & 0.164 & 0.150 & - & 0.0124 \\ 0.191 & 0.178 & 0.246 & 0.0157 & - \\ 0.192 & 0.180 & 0.355 & - & - \\ 0.202 & 0.179 & 0.362 & - & - \\ 0.200 & 0.15 & 0.466 & 0.0133 & -\end{array}$

mined points except for those cases in which the data were not adequately represented by linear correlations. In some cases the measured results suggested periodic variations of observed parameters.

In several instances, where droplets of greatly different sizes were used, observations were possible on the larger remaining droplet after the smaller droplet had burned out. In most of these cases the slope of the $D^{2}$ vs. $t$ curve changed rather abruptly for $n$-heptane droplets and yielded data in fair agreement with the known single droplet results $\left(K^{\prime} \simeq\right.$ $0.008 \mathrm{~cm}^{2} / \mathrm{sec}$ ) after the smaller droplet had burned completely. For droplets of nearly equal diameters $\left(D_{1}{ }^{0} \simeq D_{2}{ }^{0}\right)$ the evaporation constants $K_{1}^{\prime}$ and $K_{2}^{\prime}$ were found to be nearly equal. 
Table 2 Experimental results for two ethyl alcohol droplets burning in open air

$\begin{array}{lcccc}D_{1}{ }^{0}, \mathrm{~cm} & D_{2}{ }^{0} \mathrm{~cm} & C^{0}, \mathrm{~cm} & \begin{array}{c}K_{1}{ }^{\prime}, \\ \mathrm{cm}^{2} / \mathrm{sec}\end{array} & \begin{array}{c}K_{2}{ }^{\prime}, \\ \mathrm{cm}^{2} / \mathrm{sec}\end{array} \\ 0.097 & 0.091 & 0.044 & 0.0067 & 0.0053 \\ 0.100 & 0.089 & 0.199 & 0.0065 & 0.0065 \\ 0.102 & 0.095 & 0.438 & 0.0075 & 0.0070 \\ 0.104 & 0.097 & 0.032 & 0.0052 & 0.0052 \\ 0.105 & 0.104 & 0.435 & 0.0061 & 0.0063 \\ 0.108 & 0.102 & 0.298 & 0.0067 & 0.0067 \\ 0.111 & 0.104 & 0.435 & 0.0063 & 0.0063 \\ 0.109 & 0.108 & 0.773 & 0.0065 & 0.0053 \\ 0.111 & 0.109 & 0.175 & 0.0073 & 0.0057 \\ 0.111 & 0.108 & 0.438 & 0.0074 & 0.0082 \\ 0.111 & 0.108 & 0.295 & 0.0070 & 0.0067 \\ 0.123 & 0.111 & 0.166 & 0.0068 & 0.0069 \\ 0.123 & 0.117 & 0.420 & 0.0061 & 0.0066 \\ 0.138 & 0.136 & 0.184 & 0.0073 & 0.0073 \\ 0.139 & 0.137 & 0.733 & 0.0073 & 0.0074 \\ 0.143 & 0.135 & 0.132 & 0.0066 & 0.0076 \\ 0.154 & 0.150 & 0.175 & 0.0067 & 0.0061 \\ 0.156 & 0.149 & 0.653 & 0.0074 & 0.0077 \\ 0.157 & 0.150 & 0.152 & 0.0060 & 0.0059 \\ 0.160 & 0.154 & 0.181 & 0.0070 & 0.0070 \\ 0.169 & 0.169 & 0.126 & 0.0070 & 0.0066 \\ 0.172 & 0.171 & 0.132 & 0.0080 & 0.0080 \\ 0.172 & 0.172 & 0.640 & 0.0091 & 0.0091 \\ 0.174 & 0.169 & 1.010 & 0.0076 & 0.0089 \\ 0.176 & 0.172 & 0.067 & 0.0064 & 0.0066 \\ 0.177 & 0.172 & 0.184 & 0.0083 & 0.0086 \\ 0.191 & 0.187 & 0.175 & 0.0081 & 0.0077 \\ 0.190 & 0.188 & 0.333 & 0.0074 & 0.0081 \\ 0.193 & 0.186 & 0.105 & 0.0071 & 0.0069 \\ 0.193 & 0.187 & 0.181 & 0.0080 & 0.0078 \\ 0.194 & 0.193 & 0.990 & 0.0084 & 0.0087 \\ 0.199 & 0.193 & 0.175 & 0.0083 & 0.0083 \\ 0.200 & 0.196 & 0.496 & 0.0085 & 0.0085 \\ 0.201 & 0.201 & 0.296 & 0.0079 & 0.0084 \\ 0.207 & 0.204 & 0.184 & 0.0076 & 0.0076\end{array}$

Table 3 Experimental results for two methyl alcohol droplets burning in open air

$\begin{array}{lcccc}D_{1}{ }^{0}, \mathrm{~cm} & D_{2}{ }^{0}, \mathrm{~cm} & C^{0}, \mathrm{~cm} & \begin{array}{c}K_{1}{ }^{\prime}, \\ \mathrm{cm}^{2} / \mathrm{sec}\end{array} & \begin{array}{c}K_{2}{ }^{\prime}, \\ \mathrm{cm} / \mathrm{sec}\end{array} \\ 0.149 & 0.137 & \mathbf{0 . 1 2 0} & 0.0087 & 0.0078 \\ 0.146 & 0.145 & 0.128 & 0.0080 & 0.0080 \\ 0.149 & 0.148 & 0.023 & 0.0077 & 0.0077 \\ 0.149 & 0.146 & 0.426 & 0.0080 & 0.0076 \\ 0.145 & 0.137 & 0.642 & 0.0071 & 0.0073 \\ 0.140 & 0.136 & \mathbf{0 . 0 4 4} & 0.0065 & 0.0065 \\ 0.180 & 0.168 & \mathbf{0 . 1 1 7} & - & 0.0077 \\ 0.174 & 0.162 & \mathbf{0 . 4 2 6} & 0.0083 & 0.0083 \\ 0.186 & 0.169 & \mathbf{0 . 4 2 9} & 0.0084 & 0.0089 \\ 0.160 & 0.153 & \mathbf{0 . 6 9 9} & 0.0070 & 0.0076 \\ 0.204 & 0.202 & \mathbf{0 . 0 6 1} & 0.0082 & 0.0080 \\ 0.193 & 0.189 & \mathbf{0 . 5 1 1} & 0.0093 & 0.0087 \\ 0.212 & 0.200 & \mathbf{0 . 4 3 5} & 0.0082 & 0.0085\end{array}$

\section{Correlations for Evaporation Constants}

If the evaporation constant, $K^{\prime}$, of a stationary fuel droplet suspended from a quartz fiber is modified extensively by the presence of a second droplet burning in close proximity, then one might expect the value of $K^{\prime}$ to depend both on the instantaneous values of the droplet diameters and on the distance between the droplets. Contrary to this idea, it has been found that $K^{\prime}$ is constant, within the experimental limits of accuracy, for two droplets burning in close proximity.

The observed values of $\bar{K}^{\prime}=(1 / 2)\left(K_{1}{ }^{\prime}+K_{2}{ }^{\prime}\right)$, for droplets in which $D_{1}{ }^{0}$ and $D_{2}{ }^{0}$ did not differ by more than 20 per cent,

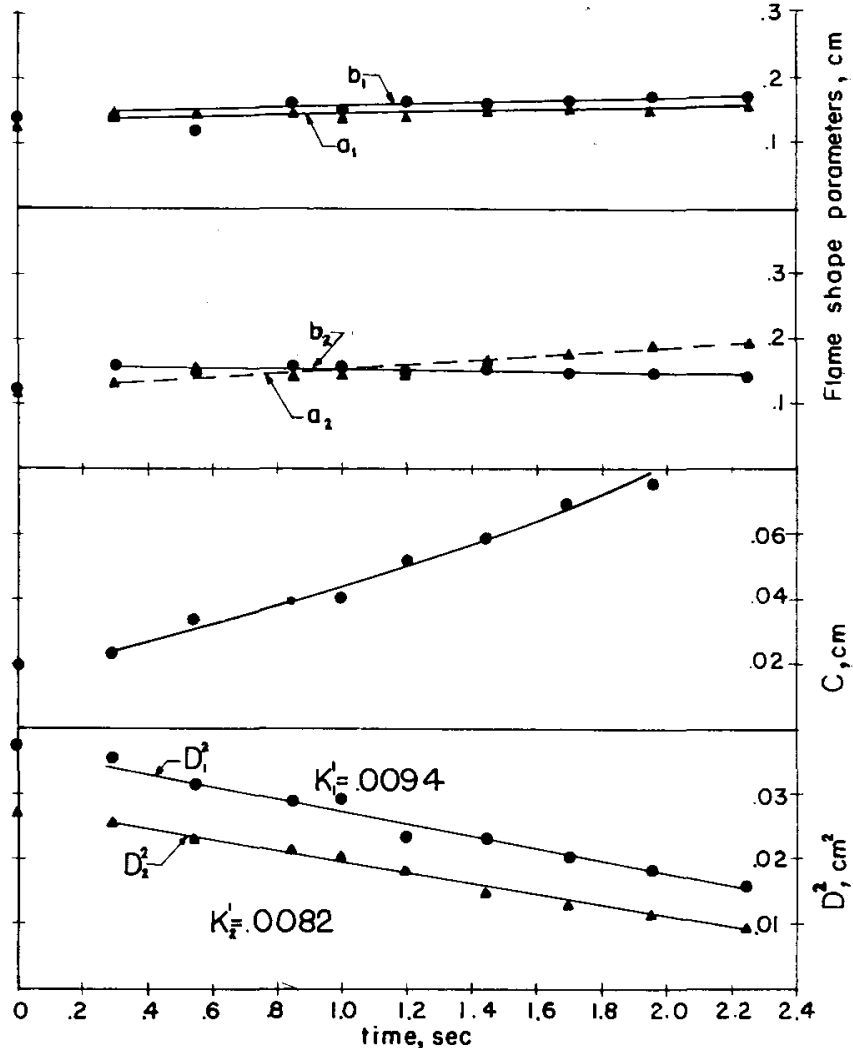

Fig. 4 Experimental results for two n-heptane droplets burning in still air

$\left(D_{1}{ }^{0}=0.194 \mathrm{~cm} ; D_{2}{ }^{0}=0.166 \mathrm{~cm} ; C^{0}=0.020 \mathrm{~cm}\right)$

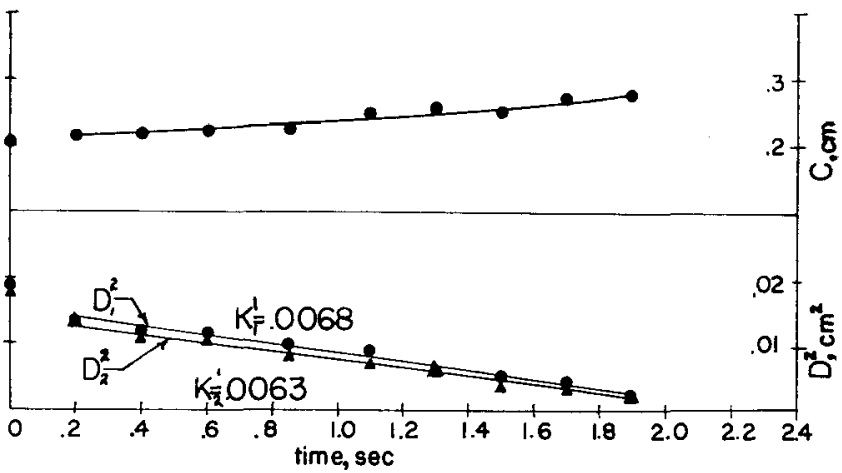

$\left(D_{1}^{\circ}=0.138 \mathrm{~cm}, D_{2}^{\circ}=0.134 \mathrm{~cm}, C^{\circ}=0.208_{\mathrm{cm}}\right)$

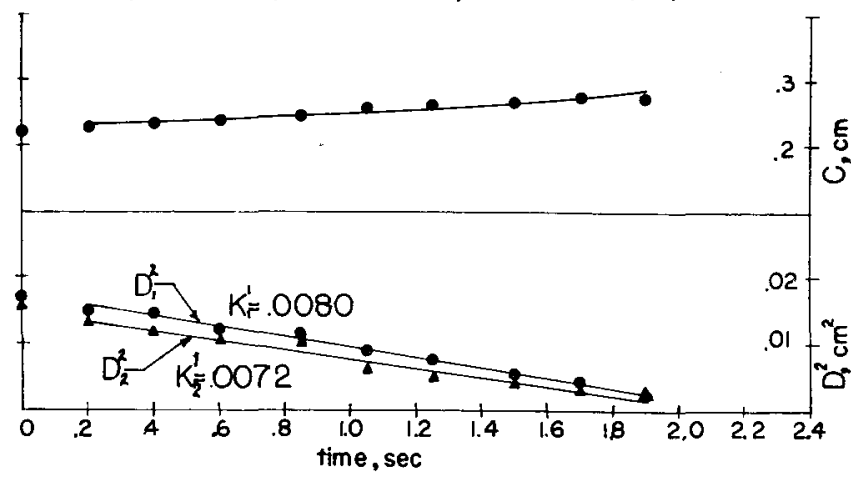

$\left(D_{i}=0.130 \mathrm{~cm}, D_{2}^{\circ}=0.127 \mathrm{~cm}, C^{\circ}=0.222 \mathrm{~cm}\right.$ )

Fig. 5 Plots of $D^{2}$ vs. time and $C$ vs. time for two n-heptane droplets burning in still air

are plotted as a function of $C^{0}$ in Figs. 11 to 13 for n-heptane, ethyl alcohol, and methyl alcohol, respectively.

Reference to Fig. 11 shows that the experimental results fall roughly into two categories depending on the initial average 


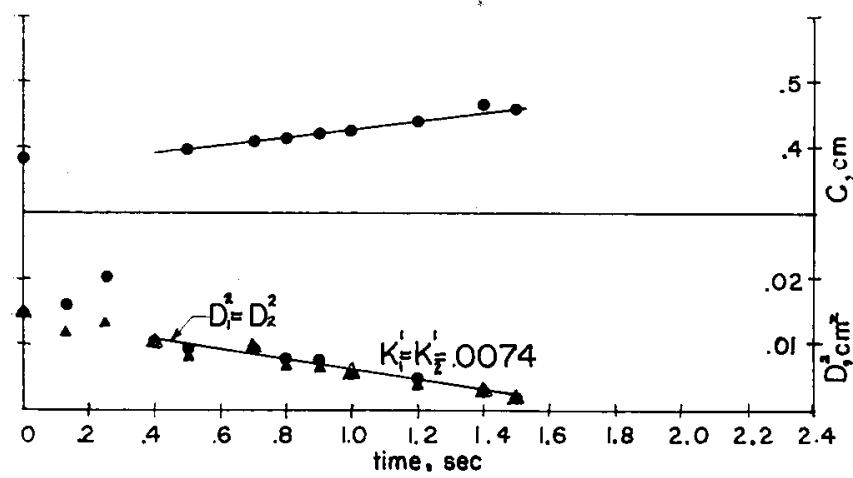

$\left(D_{1}^{\circ}=0.121 \mathrm{~cm}, D_{2}^{\circ}=0.118 \mathrm{~cm}, C^{\circ}=0.384 \mathrm{~cm}\right)$

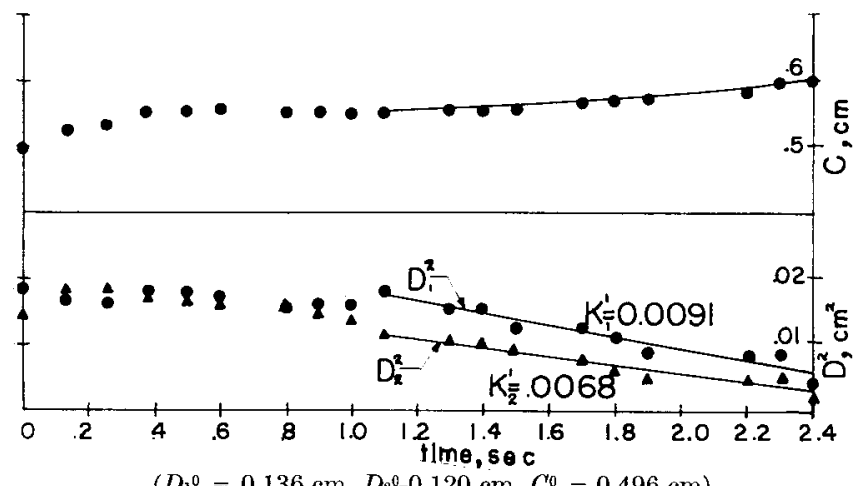

$\left(D_{1}{ }^{0}=0.136 \mathrm{~cm}, D_{2}{ }^{0}-0.120 \mathrm{~cm}, C^{0}=0.496 \mathrm{~cm}\right)$

Fig. 6 Plots of $D^{2}$ vs. time and $C$ vs. time for two n-heptane droplets burning in still air for various $C^{0}$

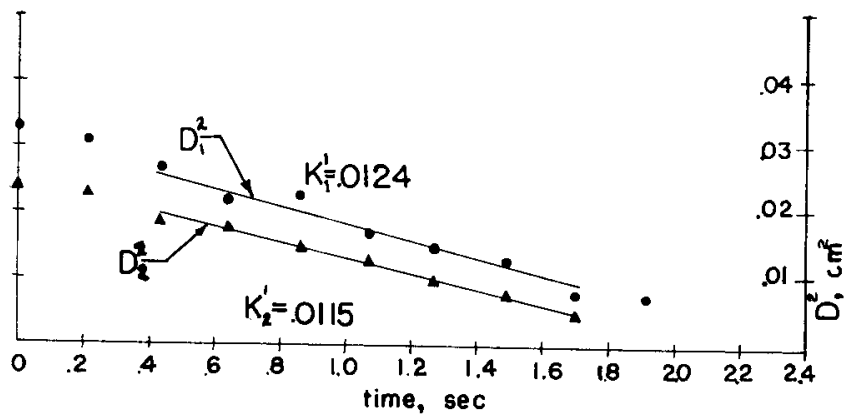

$\left(D^{\circ}=0.182 \mathrm{~cm}, D^{\circ}=0.156 \mathrm{~cm}, C^{\circ}=1.47 \mathrm{~cm}\right)$

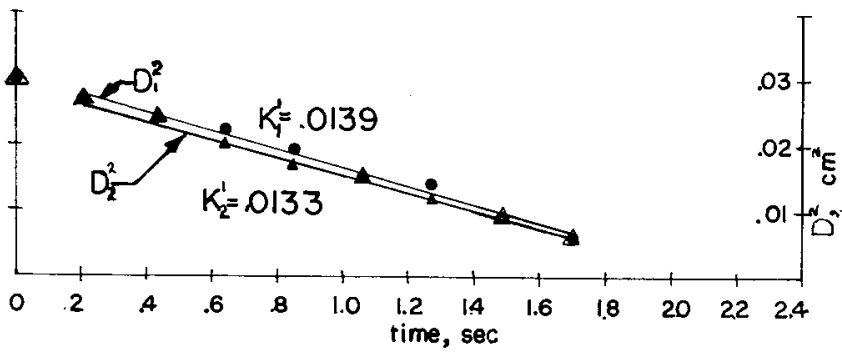

$\left(D_{1}^{\circ}=0.173 \mathrm{~cm}, D_{2}^{\circ}=0.173 \mathrm{~cm}, C^{\circ}=1.125 \mathrm{~cm}\right)$

Fig. 7 Plots of $D^{2}$ vs. time for two n-heptane droplets burning in still air

droplet diameter $\bar{D}^{0}=(1 / 2)\left(D_{1}{ }^{0}+D_{2}{ }^{0}\right)$. The average evaporation constant increases when $C^{0}$ is reduced from larger values with negligible droplet interference, presumably because heat losses from the flame surface are reduced by the proximity of a second heat source for sufficiently small values of $C^{0} ; \bar{K}^{\prime}$ reaches a maximum and then decreases again as $C^{0}$ is made still smaller. A decrease in $\bar{K}^{\prime}$ for very small values of $C^{0}$ could be produced through the creation of oxygen-deficient atmospheres resulting from increased competition for the oxygen supply furnished by convection and diffusion. On the basis of the proposed picture, the maximum in plots of $\bar{K}^{\prime}$ vs. $C^{0}$ results through a balance between two
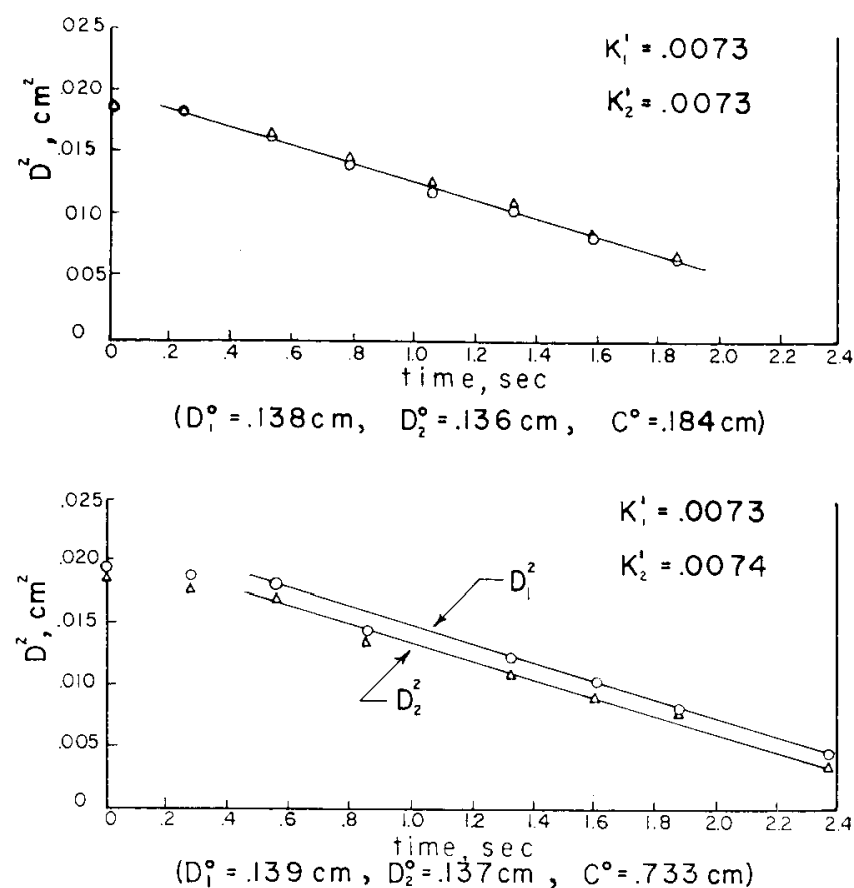

Fig. 8 Plots of $D^{2}$ vs. time for two ethyl alcohol droplets burning in still air

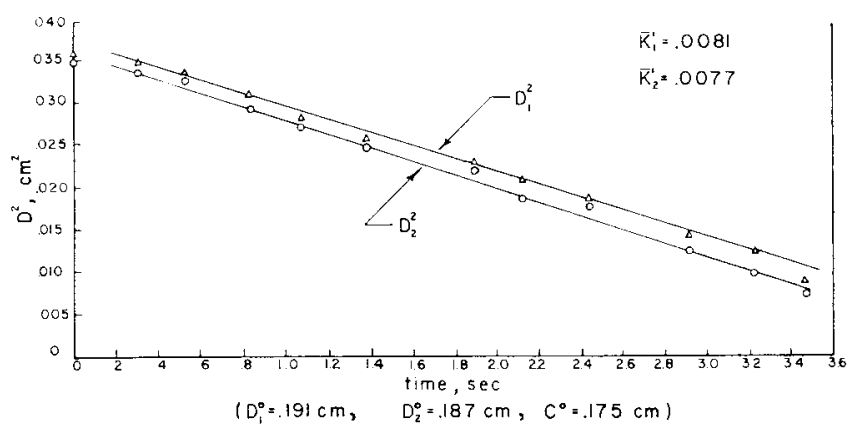

Fig. 9 Plot of $D^{2}$ vs. time for two ethyl alcohol droplets burning in still air

opposing factors, viz., decreased heat loss and decreased oxygen supply. The proposed interpretation, if applicable to spray combustion, may be of considerable practical importance.

The experimental data for $n$-heptane droplets plotted in Fig. 11 suggest a strong dependence of $\bar{K}^{\prime}$ on $\bar{D}^{0}$ unless $\bar{K}^{\prime}$ is not really constant and varies continuously during burning. In this connection it should be emphasized that changes of $\bar{K}^{\prime}$ with time correspond to changes of the second derivative in plots of $D^{2}$ vs. $t$. These second derivatives, in turn, are not defined in our studies because of unavoidable scatter of the experimental data.

The observed values of $\bar{K}^{\prime}=(1 / 2)\left(K_{1}{ }^{\prime}+K_{2}{ }^{\prime}\right)$ for ethyl and methyl alcohol droplets as a function of $C^{0}$. (see Figs. 12 and 13, respectively) do not permit any simple grouping into "small" and large droplets. It appears, furthermore, that $\bar{K}^{\prime}$ is a somewhat weaker function of $\bar{D}^{0}$ for the two alcohols than for n-heptane.

\section{A Correlations for n-Heptane Droplets}

A number of attempts were made to relate $\bar{K}^{\prime}$ with simple functions of $C^{0}, C^{0} / \bar{D}^{0}, C^{0}+\bar{D}^{0},\left(C^{0}+\bar{D}^{0}\right) / D^{0}$, etc., in order to reduce the scatter of experimental points for different values of $\bar{D}^{\circ}$. These efforts were, however, unsuccessful and suggest that the evaporation constant $\bar{K}^{\prime}$, which is independent of initial droplet diameter in single droplet studies, loses its significance as a basic correlating parameter for two nheptane droplets burning in close proximity. Whether or not this conclusion applies to sprays cannot be said without further experimental work. The fact that $\bar{K}^{\prime}$ appears to vary with $\bar{D}^{0}$ is shown more directly by plotting $\bar{K}^{\prime}$ as a func- 

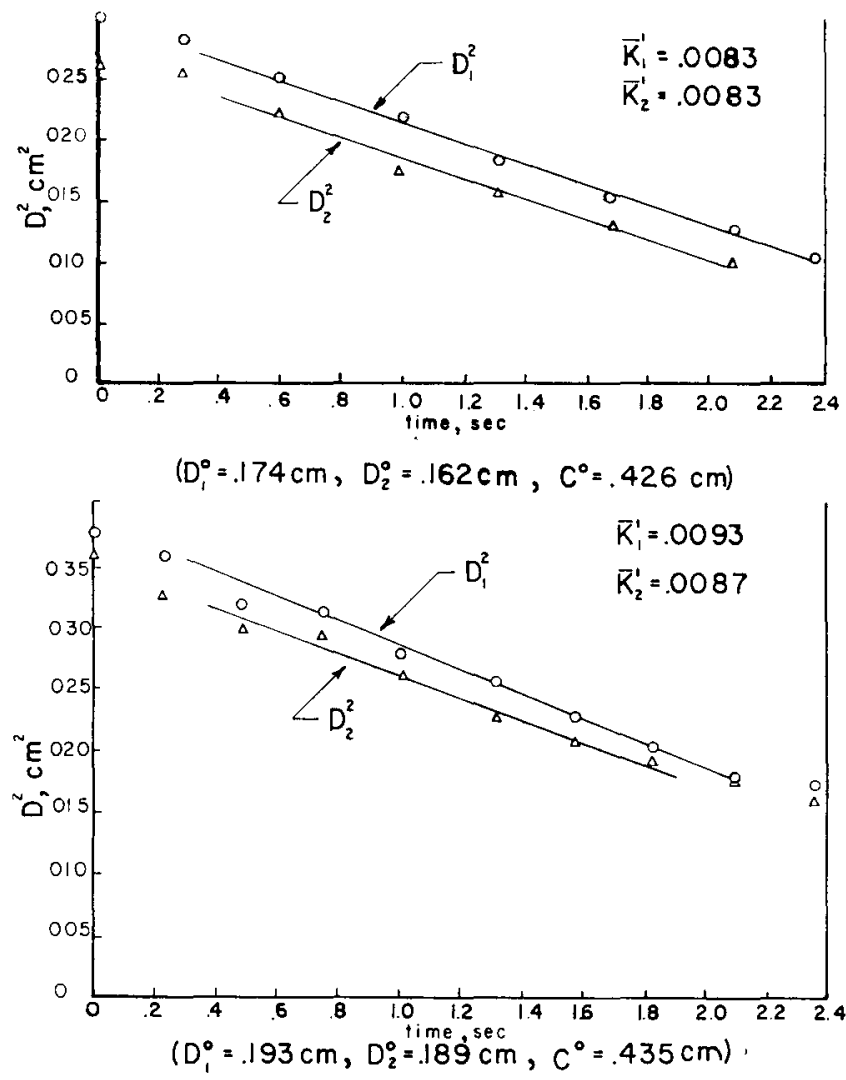

Fig. 10 Plots of $D^{2}$ vs. time for two methyl alcohol droplets burning in still air

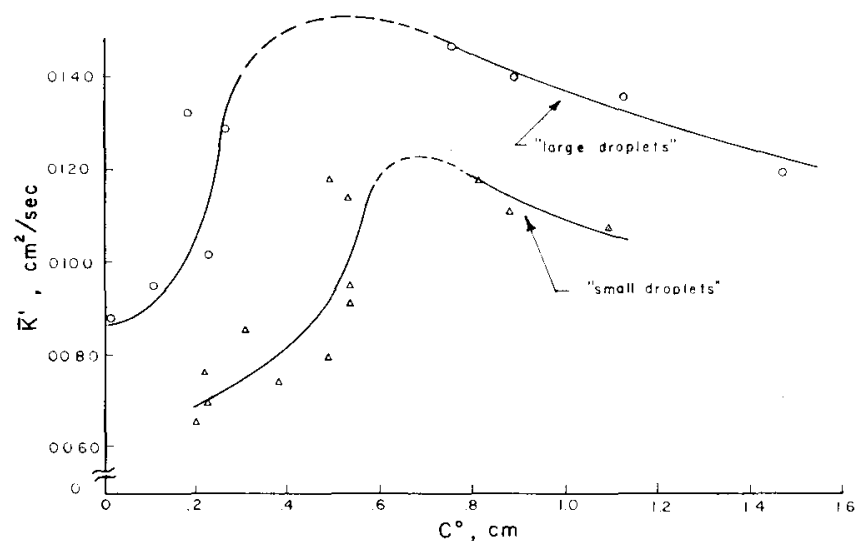

Fig. 11 Variation of the average evaporation constant with $C^{0}$ for $\mathbf{n}$-heptane droplets with different initial average diameters $\bar{D}^{\circ}$

tion of $\bar{D}^{0}$ for a group of experimental data with nearly equal values of $C^{0}+\bar{D}^{0}$.

Two burning droplets meet the requirements of geometric similarity when they have the same values of $C / \bar{D}$ and of $\bar{D}$. It is easily shown from plots of $C / \bar{D}$ vs. $\bar{D}$ that (nearly) intersecting curves are characterized by greatly different values of $\bar{K}^{\prime}$ if the values of $\bar{D}^{0}$ are different. In other words, if $\bar{K}^{\prime}$ is really constant during burning, then the value of the evaporation constant is determined primarily by the initial conditions and only to a lesser extent by geometrical arrangement.

In view of the apparent dependence of $R^{\prime}$ on $\vec{D}^{0}$, attempts were made to find a simple function of $\bar{K}^{\prime}$ and $\bar{D}^{0}$ which would depend only on $C^{0}$ or on a known function of $C^{0}$ and $\bar{D}^{0}$. An obvious choice is the ratio $\bar{K}^{\prime \prime}=\bar{K}^{\prime} /\left(\bar{D}^{0}\right)^{2}$ to which we shal] refer as the evaporation frequency.

In Fig. 14 we have plotted $\bar{K}^{\prime \prime}$ as a function of $C^{0} / \bar{D}^{0}$. Reference to Fig. 14 shows that a fair correlation of all of the experimental data has been obtained, the scatter being perhaps smaller in similar plots using $C^{0}$ and $C^{0}+\bar{D}^{0}$ as ab-

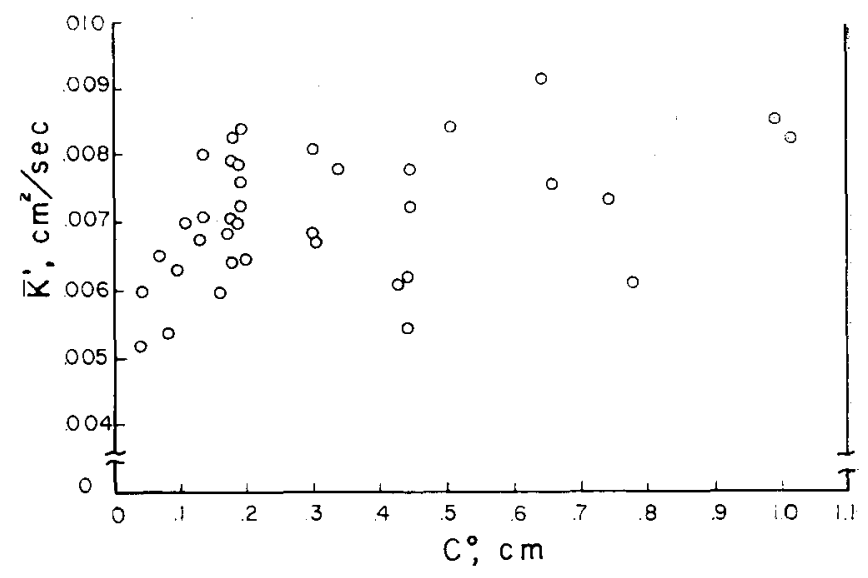

Fig. 12 Average evaporation constant vs. initial droplet spacing.

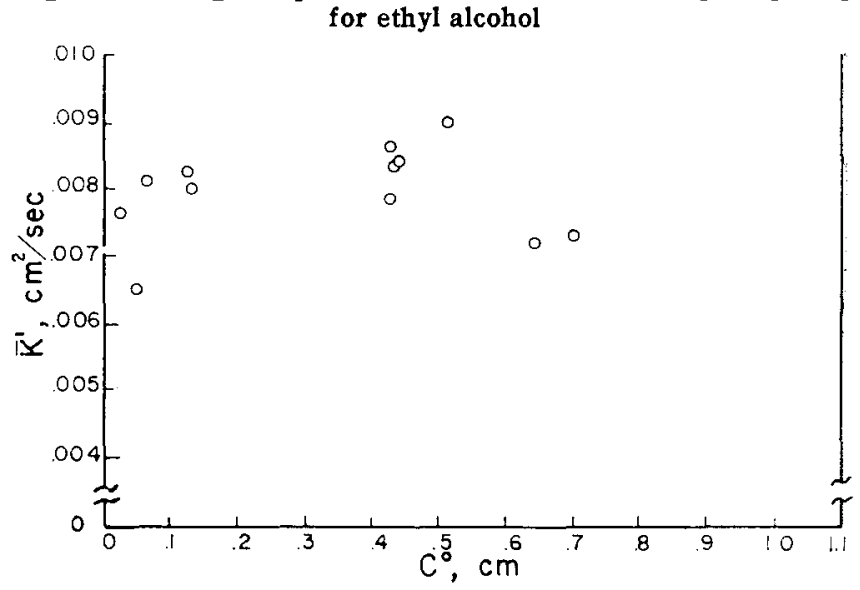

Fig. 13 Average evaporation constant vs. initial droplet spacing for ethyl alcohol

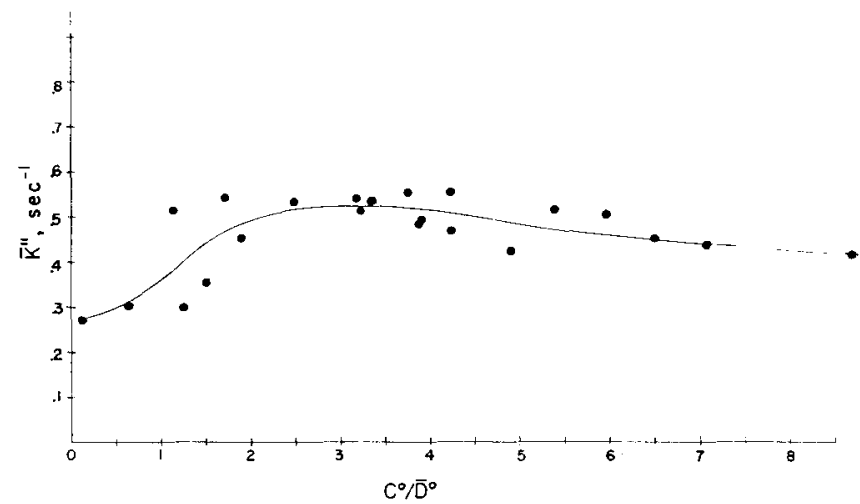

Fig. 14 Dependence of the evaporation frequency $\bar{K}^{\prime \prime}$ on $C^{0} / \bar{D}^{0}$ (n-heptane)

scissa than in the plot shown which uses the dimensionless quantity $C^{0} / \bar{D}^{0}$. In the absence of an adequate theory concerning droplet interference, the significance of the observed "correlations" is obscure, as is also any extrapolation to sprays. For this reason we must content ourselves with the observation that, for two n-heptane droplets burning in close proximity, the observed values of $\vec{K}^{\prime} /\left(\bar{D}^{0}\right)^{2}$ are fairly well represented as a function of either $C^{0} / \bar{D}^{0}, C^{0}$ or $C^{0}+\bar{D}^{0}$. Constancy of the evaporation frequency, except for variations in $C^{0}$, means that the fundamental burning rate law for fixed values of $C^{0}$ has the form

$$
(\bar{D})^{2}=\left(\bar{D}^{0}\right)^{2}-\bar{K}^{\prime \prime}\left(\bar{D}^{0}\right)^{2} \iota .
$$

\section{B Correlations for Ethyl and Methyl Alcohol Droplets}

No outstandingly successful group for correlating the observed data for $\bar{K}^{\prime}$ as a function of $\bar{D}^{0}, C^{0}$, or $C^{0} / \bar{D}^{0}$ was found for the alcohols. The fact that $\bar{K}^{\prime}$ is sensitive to changes in 


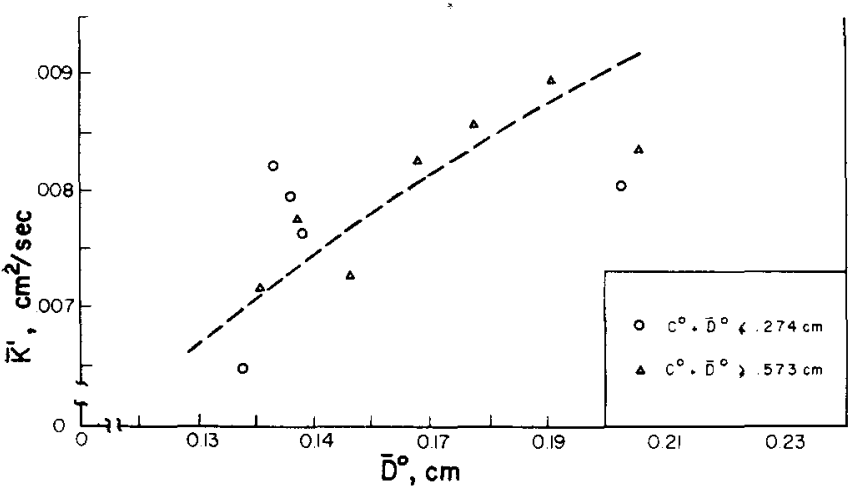

Fig. 15 Variation of $\bar{K}^{\prime}$ with $\bar{D}^{0}$ for ranges of values of $C^{0}+\bar{D}^{\circ}$ (methyl alcohol)

$\bar{D}^{\circ}$ can be seen from Figs. 15 and 16 in which curves are shown connecting the experimental results obtained for similar values of $C^{0}+\bar{D}^{0}$.

\section{Flame Shapes}

The flame shapes for two droplets, as for single droplets, are determined largely by convection currents. A qualitative description of flame shapes can be given on the basis of available experimental measurements.

\section{A Flame Shapes for Single Stationary Fuel Droplets Burning in Air}

According to an elaboration ${ }^{6}$ of observations by Kumagai and Kimura (9), a realistic description can be obtained for the flame shape surrounding a burning, single, stationary, droplet of fuel in air by allowing for the influences of free convection.

A burning fuel droplet in air must produce free convection currents. In Fig. 17 we show a schematic diagram of the flame shape for a single droplet. We shall assume that the convection veloeity corresponds to a uniform flow with velocity $U$ at some distance upstream from the initial, undisturbed, flame front. The combination of burning droplet and convective flow then acts as a source in a uniform flow field and, at steady burning, establishes the flow pattern corresponding to a half body as lower boundary. The stream surface through the lower stagnation point may be thought of as dividing initially the stream lines originating from the source (fuel droplet) and the stream lines established by convective flow. This situation is, however, unstable, and diffusive transport of oxidizer and fuel across the stream surface must be established. The tangential flow velocities at the stream surface of fuel vapor and air are initially equal. Presumably concentration and temperature gradients are established during steady burning in such a way that diffusive transport of fuel and oxygen brings a stoichiometric mixture roughly to the stream surface, thereby making the lower stream surface a flame surface.

Some of the fuel vapor is deflected around the stream surface and ultimately moves vertically upward through a cylinder of diameter $2 b$. An air flow is established parallel to the fuel flow, moving with a velocity which, in first approximation, may be assumed to be uniform and equal to $U$. Hence conditions are established for the formation of an overventilated diffusion flame and the flame height $h$ can presumably be calculated roughly from the classical treatment of Burke and Schumann for diffusion flames.

The preceding remarks may be summarized by noting that the effect of free convection is, in first approximation, a distortion of the spherical flame front to a flame surface whose

${ }^{6}$ The present discussion is based on ideas formulated by Professor L. Lees and one of us (SSP). We are indebted to Professor Lees for permission to include this material in the present report.

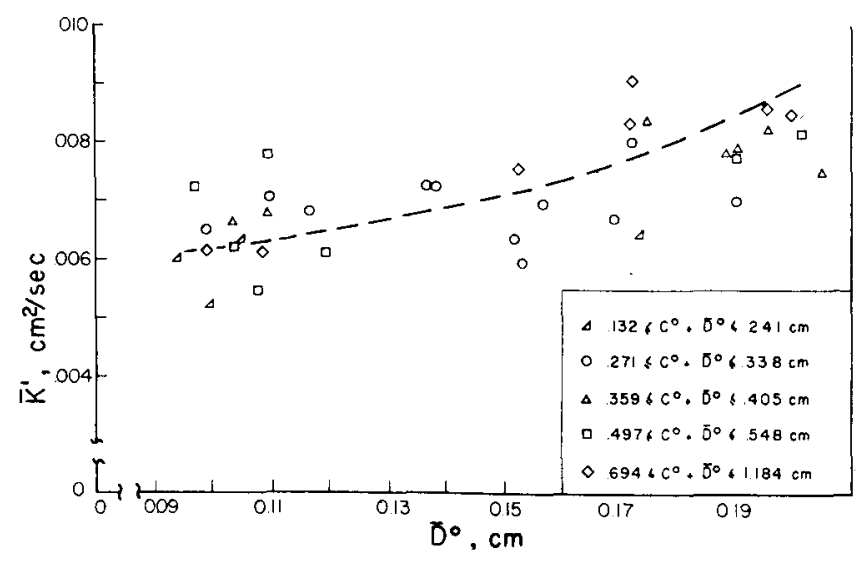

Fig. 16 Variation of $\bar{K}^{\prime}$ with $\bar{D}^{0}$ for ranges of values of $C^{0}+\bar{D}^{0}$ (ethyl alcohol)

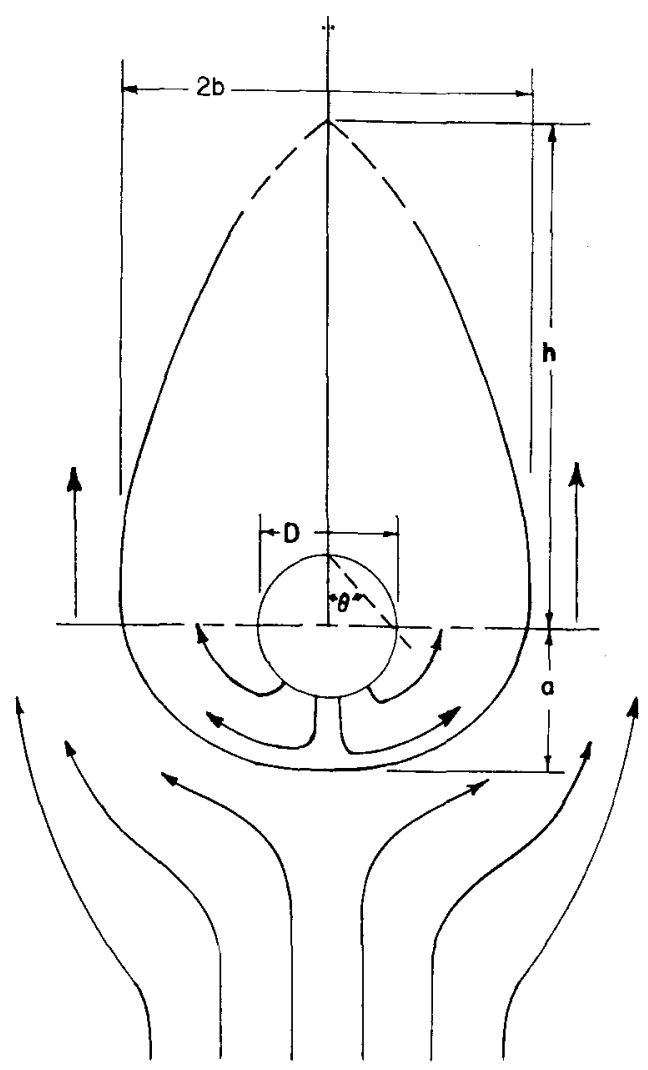

Fig. 17 Schematic diagram of burning fuel droplet. The streamlines are identified by arrows

lower boundary is the stream surface corresponding to a source of strength $\dot{m}_{F} / \rho_{F}\left(\dot{m}_{F}=\right.$ mass rate of burning of fuel droplet, $\rho_{F}=$ density of fuel vapor) in a uniform flow of velocity $U$; the upper flame surface may be described as the flame front for a cylindrical diffusion flame with the inside cylinder of diameter $2 b$ and flow velocities of fuel and air equal to $U$.

The postulated description of the flame surface leads to results which are in accord with the observations of Kumagai and Kimura.

Thus $\quad 2 b=\sqrt{2 \dot{m_{F} / S_{F} \pi U}} \ldots \ldots \ldots \ldots \ldots[4]$ and

$$
2 b / a=2 \sqrt{2}
$$

Furthermore, since $U \sin \theta$ (i.e., the tangential flow velocity of air at the stream surface) must be equal to the tangential flow velocity of fuel vapor, one would expect that $U$ and $\dot{m}_{F}$ are proportional to each other. Thus

$$
U \sim D \text {. }
$$

since $\dot{m}_{F}$ is known to be proportional to the diameter of the burning fuel droplet. Also $b / a$ should be a constant for a given 
fuel droplet and oxidizing medium; Kumagai and Kimura (9) found $b$ itself to remain unchanged for cetane oil as the droplet diameter was increased from about 0.07 to $0.12 \mathrm{~cm}$.

Although the picture of the formation of a heterogeneous diffusion flame given above seems qualitatively correct, it is apparent that a complete solution of the problem under consideration cannot be obtained without a quantitative analysis of energy transport to the droplet from the flame boundaries. However, the qualitative considerations based on the work of Kumagai and Kimura and sketched above suggest that the following important results will be obtained: (a) $\dot{m}_{F^{*}}$ weakly dependent on flame shape; (b) $U$ proportional to $D$; (c) $h$ proportional to $b^{2} D$; (d) $b$ weakly dependent on $D$.

\section{B Flame Shapes for Two n-Heptane Droplets Burning in} Close Proximity

For two n-heptane droplets burning in close proximity, it has already been noted that $a_{1}, b_{1}, a_{2}$, and $b_{2}$ change very little during droplet burning. Furthermore, reference to the original experimental data shows that the ratio of $b$ to $a$ is not sensibly different from unity and does not seem to depend strongly on $C^{0}$. In some cases the distances of the flame surfaces from the droplet surfaces remained constant during burning (see Fig. 2).

The droplet spacing parameter $C$ is, of course, determined through the geometric arrangement. Thus

$$
C=C^{0}+(1 / 2)\left(D_{1}^{0}-D_{1}\right)+(1 / 2)\left(D_{2}^{0}-D_{2}\right)
$$

or

$$
\begin{aligned}
C=c^{0}+(1 / 2) D_{1}^{0}\left(1-\sqrt{K_{1}{ }^{\prime} t /\left(D_{1}\right)^{2}}\right)+ \\
(1 / 2) D_{2}{ }^{0}\left(1-\sqrt{K_{2} t /\left(D_{2}{ }^{0}\right)^{2}}\right) \ldots \ldots
\end{aligned}
$$

Needless to say, the time dependence of $C$ is well represented by Fquation [7].

\section{Dimensional Analysis Relating to the Burning of Liquid Droplets}

Since the experimental data obtained in the present investigations are not intelligible on the basis of existing theoretical studies for the burning of single fuel droplets (4), it is of interest to re-examine the problem at least qualitatively in an effort to understand the dimensionless groups which govern droplet burning. We take the detailed theoretical studies for single droplets as a guide in this work. In view of the observed importance of chemical effects, which is emphasized by the differences between the alcohols and $n$-heptane, we cannot expect a complete answer without introducing explicitly dimensionless groups depending on chemical reaction rates. We note, however, that existing theoretical studies must be deficient since, for example, no really satisfactory explanation exists for the variation of burning rate with pressure.

\section{A The Burning of Single Droplets}

The burning of a single stationary fuel droplet in an oxidizing atmosphere involves the following 23 variables: Mass burning rate of fuel droplet $\dot{m}_{F}$; stoichiometric ratio of mass of $\mathrm{O}_{2}$ burnt for unit mass of fuel burnt, $\nu$; constant pressure $p$; specific latent heat of evaporation of fuel droplet $\Delta l$; standard specific enthalpy difference between reactants and reaction products $q$; droplet diameter $D$; specific heats at constant pressure $C_{p, l}, C_{p, P}, C_{p, F}$ and $C_{p, o}$; densities $\rho_{l}, \rho_{f}$, and $\rho_{A} ;$ temperatures $T_{l}, T_{c}$, and $T_{O}=T_{A}$; thermal conductivities $\lambda_{F}$ and $\lambda_{A}$; viscosity coefficients $\eta_{F}, \eta_{O}$, and $\eta_{A}$; diffusion coefficients $D_{F}$ and $D_{O}$. Here the subscripts $l, P, F, O$, and $A$ identify liquid fuel, combustion products, gaseous fuel, oxygen, and air, respectively. The temperature $T_{c}$ is the temperature at the reaction surface. In our physical model the system is characterized by average diffusion, viscosity, and thermal conduction coefficients on the fuel and air sides of the flame front. A suitable set of 18 dimensionless groups ${ }^{7}$ is the following: Schmidt number $S c=\eta_{F} / \rho_{F} D_{F}$, Prandtl number

$$
\begin{gathered}
\operatorname{Pr}=\eta_{F} c_{p, F} / \lambda_{F}, \rho_{l} / \rho_{F}, \rho_{A} / \rho_{F}, c_{p, F}\left(T_{C}-T_{l}\right) / \Delta l, D_{o} / D_{F} \\
\lambda_{o} / \lambda_{F}, \eta_{O} / \eta_{F}, \eta_{A} / \eta_{F}, c_{p, o} / c_{p, F}, c_{p, P} / c_{p, F}, c_{p, l} / c_{p, F}, \nu \\
q / \Delta l,\left(T_{c}-T_{O}\right) /\left(T_{e}-T_{l}\right), p_{A} / \rho_{A} R_{A} T_{O}
\end{gathered}
$$

where $R_{A}$ is the gas constant per gram of air, the Grashof number ${ }^{8} G r=D^{3} \rho^{2} g \beta^{\prime}\left(T_{c}-T_{o}\right) / \eta_{A}{ }^{2}$ where $g$ is the acceleration of gravity and $\beta^{\prime}$ the coefficient of expansion of air, and $K^{\prime} / D_{F}$ with $K^{\prime}=-d\left(D^{2}\right) / d t$ as the evaporation constant.

From the conservation of mass equations it is apparent that

$$
\dot{m}_{F}=-\frac{d}{d t}\left(\frac{\pi}{6} D^{3} \rho_{l}\right)=\frac{\pi}{4} \rho_{l} D K^{\prime}
$$

whence

$$
K^{\prime} / D_{F}=4 \dot{m}_{F} / \pi \rho_{l} D D_{F}
$$

From the analytic solution (4) for $\dot{m}_{F}$ (using constant average values for specific heats and thermal conductivities) it is easily shown that

$$
\frac{K^{\prime}}{D_{F}}=\frac{8(S c)}{(P r)}\left(\frac{\rho_{F}}{\rho_{l}}\right) \frac{\ln \left[1+c_{p, F}\left(T_{c}-T_{l}\right) / \Delta l\right]}{\left[1-\left(r_{l} / r_{c}\right)\right]}
$$

where $r_{l} / r_{c}$ represents the ratio of the radius of the fuel droplet to the radius of the flame surface. The ratio $r_{l} / r_{c}$ is a complicated function of several of the dimensionless groups listed previously. By utilizing experimental results obtained for the burning of single droplets we are now able to draw some useful qualitative conclusions.

It has been found that $K^{\prime}$ is constant during burning and is therefore independent of the instantaneous value of $D$. Reference to the 18 dimensionless groups shows that only $G r$, which determines the magnitude of the convection currents, is a function of $D$. The constancy of $K^{\prime}$ during burning therefore suggests that the convection currents induced during burning have no important effect on $K^{\prime}$. This observation is in agreement with the result that absolute values calculated for $K^{\prime}$, without considering the influence of convection, are in fair agreement with experimental measurements (4). The functional relation given in Equation [9] also involves the assumption that convection effects may be neglected in first approximation.

Reference to Equation [9] shows that $K^{\prime}$ is a linear function of $\rho_{F} D_{F}$ and of other terms which are pressure independent, except possibly for $r_{l} / r_{c}$. It has been found experimentally (3) that $K^{\prime}$ varies as $p^{1 / 4}$. Hence, in terms of the simple picture used in the derivation of Equation [9], it follows that $\left[1-\left(r_{l} / r_{c}\right)\right]$ must vary as $p^{-1 / 4}$ in order to account for the observed variation of $K^{\prime}$ with pressure " In a more general analysis, in which proper allowance is made for radiant heat transfer and which does not involve the assumption that chemical reactions are fast compared with the transport processes, a dependence of $K^{\prime}$ on pressure may be introduced through the effect of pressure on radiant energy transport or through pressure-sensitive chemical reaction rates. There is an obvious difficulty in attempting to account for the pressure variation of $K^{\prime}$ through the influence of the Grashof number and free convection currents. Thus, since $K^{\prime}$ is constant during burning, it must be independent of (droplet or) com-

\footnotetext{
${ }^{7}$ According to the Buckingham Pi theorem, the number of dimensionless groups usually equals the number of variables minus the number of dimensions. There are five dimensions in the present problem: length, time, mass, temperature, heat.

${ }^{8}$ The Grashof number may well involve the diameter of the combustion surface, $2 r_{c}$, rather than $D=2 r_{l}$. Since $r_{c}$ and $r_{l}$ are related, this change will not affect the following arguments.
} 
bustion surface diameter. But $K^{\prime}$ is a more sensitive function of this length than of pressure. Therefore, the pressure dependence of $K^{\prime}$ should probably not be attributed to the influence of $G r .^{9}$

\section{B Two Droplets Burning in Close Proximity}

For two droplets of equal size, whose centers are separated by a distance $C^{0}+\bar{D}^{0}$, we have the additional variable $C^{0}+$ $\bar{D}^{0}$ and the new dimensionless group $D /\left(C^{0}+\bar{D}^{0}\right)$, where $D$ is the diameter of the burning droplets. Since it has been found experimentally that $K^{\prime}$ for each of the two droplets is also independent of the instantaneous value of $D$, it seems likely that convection effects are again of secondary importance. However, $K^{\prime}$ may not be a function of $D /\left(C^{0}+\right.$ $\bar{D}^{0}$ ) but rather of the initial drop diameter $\bar{D}^{0}$ itself (with the exact dependence varying with fuel type). This result is difficult to understand since it suggests that the entire burning process is influenced by the initial configuration unless, of course, $K^{\prime}$ is not really constant during burning but varies so little that its change with time (i.e., the change of the second derivative in a plot of $D^{2}$ vs. time) cannot be detected with certainty. If $K^{\prime}$ is really constant during burning, then we are dealing again with a fundamental problem similar to that involved in the pressure dependence of $K^{\prime}$ for single droplets. Questions of this sort are not answered by dimensional studies alone.

\section{Five Droplets Burning in Close Proximity}

Some experimental data have been obtained also for the burning of an array of five ethyl alcohol droplets in air. Four of the droplets were located at the corners of a square and the fifth in the center of the square. The square of the diameter for the droplet surrounded by four other droplets was again found to decrease linearly with time, with the apparent value of $K^{\prime}$ about 20 per cent larger than for similar studies on two droplets burning in close proximity. ${ }^{10}$ The work has not yet progressed to the point where the variables determining the absolute value of $K^{\prime}$ are properly defined.

\section{Conclusions}

The most important results obtained in the present investigations are the following: (a) within the limits of experimental accuracy, the evaporation constant $K^{\prime}$ is invariant with

${ }^{9}$ The effect of pressure on convective heat transfer to burning droplets has been discussed, for example, by Wise, Lorell and Wood (Fifth Symposium on Combustion, pp. 139-140, Reinhold Publishing Corporation, New York, N. Y.). Goldsmith and Perkins (5) have found that the mass burning rate of single droplets is a weak function of air velocity in forced convection experiments. Finally, current experimental results suggest that $K^{\prime}$ varies as a weak power of the pressure with the exponent dependent on fuel type.

${ }^{10}$ Recent preliminary experiments by Lt. J. Kanevsky on nine droplets arranged in a body-centered cubic lattice have again led to the conclusion that, for the center droplet, the square of drop diameter decreases linearly with time. time for two droplets burning in close proximity and also for the center droplet of a five-droplet array; (b) the absolute value of $K^{\prime}$ is not determined by chemical composition alone but depends also on droplet arrangement. The first conclusion is of considerable practical interest since it supports the type of phenomenological considerations used by Probert for analyzing spray combustion. In general, it appears unlikely that $D^{2}$ will not decrease linearly with time, in good approximation, for arrays and sprays which are more complicated than those considered by us. The second conclusion underlines the doubts expressed in our introduction about the practical value of results derived from studies on single droplets and simple droplet arrays. In fact, if $K^{\prime}$ is really dependent on injector design, then it would be better to curry out fundamental studies on spray combustion with injector configurations of the type used in service models. An over-all description of combustion rates in terms of parameters such as an average $K^{\prime}$ for a spray and an average residence time $t_{r}$ for all of the droplets is sufficient for practical purposes. Quantitative predictions of absolute values for $K^{\prime}$ in sprays must await more detailed understanding of the importance of chemical reaction rates and convection effects than we shall possess for a long time to come.

\section{References}

1 Godsave, G. A. E., "The Burning of Single Drops of Fuel: Part I, Temperature Distribution and Heat Transfer in PreFlame Region," National Gas Turbine Establishment (England) Report no. R. 66, 1950.

2 Godsave, G. A. E., "The Burning of Single Drops of Fuel: Part II, Experimental Results," National Gas Turbine Establishment (England) Report no. R. 87, 1951.

3 Hall, A. R., and Diederichsen, J., "An Experimental Study of the Burning of Single Drops of Fuel in Air at Pressures up to Twenty Atmospheres," Fourth (International) Symposium on Combustion, Williams and Wilkins Co., Baltimore, 1953, pp. $837-846$.

4 Goldsmith, M., and Penner, S. S., "On the Burning of Single Drops of Fuel in an Oxidizing Atmosphere," Jet PropulsIoN, vol. 24, 1954, pp. 245-251. See also "Introduction to the Study of Chemical Reactions in Flow Systems," by S. S. Penner, Butterworths Scientific Pub., Ltd., London 1955, Chap. 4.

5 Goldsmith, M., and Perkins, C. K., "Experiments on the Burning of Single Drops of Fuel in Oxygen-Inert Gas Mixtures," Technical Report No. 4, Contract No. DA 04-495-Ord-446, California Institute of Technology, May 1954.

6 Graves, C. C., and Gerstein, M., "Some Aspects of the Combustion of Liquid Fuels," in Combustion Researches and Reviews, 1955, Butterworths Scientific Publications, Ltd., London 1955; Chapter 3.

7 Probert, R. P., "The Influence of Spray Particle Size and Distribution in the Combustion of Oil Droplets," Philosophical Magazine, Vol. 37, 1953, pp. 94-105.

8 Tanasawa, Y., "On the Combustion Rate of a Group of Fuel Particles Injected Through a Swirl Nozzle," Technology Reports of Tohoku University, vol. 18, 1954, pp. 195-208, Sendai, Japan.

9 Kumagai, S., and Kimura, I., "Combustion of Fuel Droplets," Science of Machine, vol. 3, 1951, pp. 431-434. 